\title{
Una interpretación del cuento "La carta robada" de Edgar Allan Poe
}

An interpretation of the story "T he purloined letter" by Edgar Allan Poe

Roberto Angel G.

Pontificia Universidad $C$ atólica de $C$ hile

E-mail: rangel@uc.cl

R OLAN D Barthes (1990) en La aventura semiológica señala que el lenguaje $R$ es a la vez estructurado e infinito. Esto que podría parecer una contradicción no sería tal ya que, como propone Barthes, cada texto sería posible de ser interpretado de ilimitadas formas, cada una de las cuales poseería su propia organización y significancia con respecto a sus contenidos.

Entonces podríamos preguntarnos ¿Sería única y correcta la proposición de Lacan (1984) cuando afirma, en "El seminario de 'La carta robada', que lo que quiere decir "la carta robada", es que una carta llega siempre a su destino? La respuesta de Barthes debería de ser sí y no. Sí, porque Lacan ha hilvanado una serie de situaciones bajo las cuales su interpretación sería la acertada. No, porque existirían innumerables más.

D e esta forma, para Barthes el éxito del análisis estructural no va a depender del carácter inequívoco de sus resultados, sino más bien de su capacidad de asociación de los códigos que se manifiesten en la lectura del texto. Así, la aspiración de este trabajo estará lejos de pretender encontrar un sentido único en el cuento, sino por el contrario, dinamitarlo hacia otras posibles apreciaciones que enriquezcan su lectura.

Toda carta quepretende ser coherente debiera de poseer un texto impreso en ella. En el caso de nuestro cuento no se nos revela su contenido, pero sí es posible inferir que se trataría de una carta que compromete la relación de la reina con su rey, tal vez la de un amante 0 una carta de amor. Por otro lado, sabemos bien que la palabra "letter" en inglés es posible traducirla al español como "carta" y como "letra". Bajo estas dos consideraciones, propongo que lo que se le ha extraviado a la reina, y de paso al detective D upin, corresponde a la 
escritura1", cuyo origen es la "letra", y que, tras un descuido, ha sido sustraída por un burgués con el único objetivo de sacar provecho de ella.

La escena del robo se produce en el despacho real. La reina ha recibido la carta de un presunto amantey de pronto hace su aparición el rey, quien, descuidado, no advierte la existencia de la simulación. ¿Pero, es acaso que el rey no se ha percatado de la situación o, para no atraer hacia su persona un desagradable percance que podría irremediablemente retrasar e importunar sus impostergables asuntos prefiere deliberadamente ignorar el desconcierto de su reina? Q uien posee ahora la escritura es la reina. El tema, como dijimos, no importa. Puede ser cualquiera de los infinitos de la literatura. Tampoco el autor, del cual nunca sabremos si existe.

Poe era un escritor desencantado tanto de la literatura como de la sociedad norteamericana de su tiempo. Julio Cortázar (1987), en la introducción de los Ensayos y críticas de Poe, explica que el ideal ismo proveniente de Europa jamás pudo interponerse a la conquista de los dólares originada en la N ueva Inglaterra y que muchos escritores poseían un doble estándar en el que por un lado aceptaban el trascendentalismo, pero por otro se veían satisfechos con las prácticas sociales. Así Poe no va a cejar nunca de combatir con duras críticas este aburguesamiento de la literatura de su país, buscando siempre un fin artístico superior en sus obras.

D esde esta perspectiva podemos ver a "La carta robada" como una solapada queja de Poe hacia la burguesía y literatura de su tiempo. ¿Q uién es el rey sino aquel diligente hombre de negocios que reconoce la importancia de carta, pero que a la vez desconoce por tener responsabilidades más importantes que resolver?

Es aquí donde entra al juego el otro actor que nos interesa. Se trata del $M$ inistro $D$., quien, al percatarse del turbamiento de la reina, hurta el comprometedor documento ante los incrédulos ojos de ella, quien ya sabe que es él quien le ha robado. ¿Pero qué beneficio obtiene $D$. al tomar posesión de la carta? La posibilidad de utilizarla como chantaje ante la reina y de este modo sacar como provecho el escalar posiciones en su alto rango político. Recordemos que en nuestro análisis la carta representa a la literatura. Así D ., poeta y matemático, pasa a ser el escritor aburguesado tan duramente criticado por Poe, quien toma posesión de la escritura no para otra cosa sino para una conveniencia personal de prestigio, al igual que aquellos literatos contemporáneos a Poe que, conscientes del poder material del auge industrial de Norteamérica, no

\footnotetext{
${ }^{1}$ En adelante, para referirme a la carta robada también utilizaré la palabra literatura, arte 0 poesía, siempre enmarcada bajo este contexto.
} 
hacían otra cosa sino disfrazar sus textos a favor de un cierto entusiasmo por el crecimiento científico y económico, adulando al fin y al cabo a la masa.

U na vez sustraída la carta será la policía, representada por el prefecto G., quien será la encargada de su restitución. En el cuento se explica el prolijo procedimiento que llevan a cabo los hombres de G .: centímetro por centímetro, cuadriculando el espacio, han registrado todo los intersticios de la casa del M inistro D. La pregunta al respecto que realiza Lacan (1984) en su ensayo es una observación que no podría haber escapado a ningún lector curioso. Lacan señala lo siguiente: "¿N o tenemos entonces derecho a preguntar cómo es posibleque la carta no se haya encontrado en ningún sitio... puesto que el campo que éstas agotaron [las búsquedas] la contenía de hecho como lo probó finalmente el hallazgo de Dupin?" (Lacan, 1984: 17). En efecto, ¿cómo es posible que las pesquisas de la policía no hayan surtido efecto, si la carta estaba dentro del área del minucioso registro?

Esta pregunta generaría dos posibles respuestas: primero, que el prefecto $\mathrm{G}$. realmente no hubiera hallado la carta, con lo cual se compartiría lo que el texto señala: que el procedimiento de la policía no es el adecuado, ya que buscan en donde es evidente que se podría ocultar un objeto.

Por otro lado, también podría pensarse que la policía no deseara verdaderamente encontrar el documento (en el caso que quisiéramos dar una respuesta fiel a la sincera pregunta de Lacan), ya que, como emblemas del orden y súbditos de la ley, no querrían averiguar lo que a propósito el rey ha querido olvidar. Tal vez D upin, gracias a su exquisita intuición, ya se había percatado de esto y en el momento que el prefecto $\mathrm{G}$. se dispone a continuar el relato del crimen, Dupin se apura a interrumpirlo advirtiéndole "O no prosiga... " (Poe, 1987: 19), como querien do decirle al prefecto que si en verdad no pretende encontrar la carta es mejor que no le revele los detalles del suceso.

Cualquiera sea la respuesta que mejor le acomode al lector, el asunto es que la literatura ha quedado de esta forma en manos de un escritor burgués. D upin será el encargado de redimirla y devolverla al sitial del cual jamás debió de haber salido: junto a la reina.

¿D e qué forma $D$ upin recuperará el documento? ¿Q ué premisas serán las adecuadas para llevar esto a cabo? Para Poe la literatura y el arte deberán ser fidedignos representantes de una realidad que está más allá de aquella primera fútil visión. En Poe: Estudio crítico, Edward D avidson (1960) señala que todo enigma otorga la posibilidad de reconstruir aquella existencia primera bajo la cual están supeditadas las cosas. D avidson explica quetodo "crimen es el rompimiento del orden aparente delas cosas... y es, por consiguiente, como descubrir por un momento lo ideal, la naturaleza verdadera delas cosas" (D avidson, 1960: 
227). Para $D$ avidson el poeta sería similar al detective, ya que de una raíz confusa ambos serían capaces de esclarecer la verdad oculta. En Poe, este descubrimiento del ideal, esta recuperación de la escritura, estará, como veremos en adelante, rodeada por la influencia del pensamiento romántico alemán.

D upin explica que uno de los problemas para acceder a la solución de los enigmas es el exacerbado abuso de la lógica matemática. Emparentándose con las ideas de Schlegel y el círculo de filósofos de Jena, D upin señala que "el razonamiento matemático no es otra cosa que la lógica aplicada a la observación de la forma y la cantidad. El error consiste en suponer que las verdades de lo que llamamos álgebra pura, son verdades abstractas o generales" (Poe, 1987: 33).

Por lo tanto, para llegar al origen, Poe considerará, al igual que los románticos alemanes, la unión entre las matemáticas (la ciencia) y la poesía (el sentimiento y la intuición).

La figura del poeta será central en el cuento de Poe. Por un lado será visto por una parte de la sociedad, representada en el prefecto G ., como un desperdicio ante la praxis de la realidad, ineficaz a la hora de resolver cualquier proble ma: "No será un insensato... pero es un poeta, lo queno es muy distinto" (Poe, 1987: 23), dirá G . al referirse al M inistro D. Pero Poe lo reivindicará constante mente, proyectándolo más como un personaje prudente y furtivo que como un necio. Refiriéndose nuevamente al M inistro D., D upin dirá: "Como poeta y matemático habría razonado bien. Como simple matemático no habría razonado..." (Poe, 1987: 32).

Encarnado en Dupin, el poeta también será aquel que verdaderamente ve los hechos, pero que premeditadamente se descubre como al guien que no puede hacerlo. Esta será la función de los lentes que vestirá $D$ upin en su visita a D . y antelo cual señalará: "Para no ser menos, me quejé de la debilidad de mi vista y deploré la necesidad de usar anteojos" (Poe, 1987: 36).

También el poeta será el loco que ha perdido el juicio, locura que Poe valorará, ya que para él no representará la pérdida de la lucidez, sino que un grado de la inteligencia. Esto se ejemplifica en el hombre del fusil, doble de Dupin, quien dispara su arma en plena calle para desconcentrar $a \mathrm{D}$. en el momento de la recuperación de la carta: "... le permitieron que siguiera como un lunático 0 un ebrio... el supuesto lunático era, naturalmente, un empleado mío" (Poe, 1987: 38), dirá Dupin al relatar el hecho. Es decir, D upin estará en todo momento consciente de su locura que, como a un obediente y eficaz funcionario, impartirá instrucciones precisas con el fin de desentrañar los enigmas de la realidad.

Pero no sólo deberán fundirse ciencia y poesía para alcanzar la solución del misterio, también el hombre tendrá que fusionarse con la naturaleza para asir la verdadera realidad. Poe pensaba que la mente humana estaba fuertemente 
correlacionada con las manifestaciones que en la naturaleza podían encontrarse. Como explica D avidson (1960), esta unidad no se encontraría en la experiencia tangible en la cual vive el hombre, sino que se ubicaría en el orden último de la mente y la materia, fuente primigenia de los sucesos.

Si la manera en que razona la inteligencia humana está directamente relacionada con la manera en que suceden las cosas en la naturaleza, entonces D upin puedeconjeturar queal analizar el comportamiento del otro es posiblellegar, en base a un idealismo, a la resolución del crimen. Es la estrategia que utiliza el astuto niño que siempre gana en el juego de par e impar: “¿En qué consistía el procedimiento de este niño a quien llamaban afortunado los compañeros? Consistía... en la identificación de su inteligencia con la del contrario" (Poe, 1987: 29).

D e este modo, en el momento de su visita al M inistro D . en su casa, D upin estará actuando del mismo modo que lo hace el afortunado muchachito del juego de par e impar: al reconocer la forma de razonar del M inistro D . logrará resolver el crimen, pues así encontrará la fuente misma del misterio.

Es así como Dupin, teniendo conciencia de sus dos premisas, la unidad entre la ciencia y la poesía y la unión entre la mente y la naturaleza, descifrará el escondite en el cual seha al bergado la carta durantetanto tiempo: "M is ojos, ya recorrido todo el cuarto, dieron con una miserable tarjetera de cartón, que pendía de una cinta azul, sobre la chimenea" (Poe, 1987: 36). Q ue la carta robada estéen un lugar cualquiera, demasiado sencillo para su encubrimiento, no quiere representar sino aquel prístino lugar, tan caro para los románticos, en el cual todas las cosas se funden y en el cual se encuentra, investida de clásica sencillez, la verdadera poesía y el verdadero arte.

Tampoco puede pasar desapercibida aquella "cinta azul" desde la cual pende el enigma: Poe estaría realizando un proceso similar al que lleva a cabo $\mathrm{N}$ oval is bajo el nombre de "romantizar el mundo" y cuyo símbolo es "la flor azul", el azul del infinito remontado al origen de los románticos.

¿Q ué será de la suerte de nuestro escritor burgués, desvirtuador y comerciante del arte? Es lo que menos importa a D upin, quien dice: "En este caso, no tengo simpatíani piedad por el hombre que desciende. Es el monstrum horrendum, es el hombre genial, inescrupuloso" (Poe, 1987: 39), quien utiliza sus dones literarios y su ingenio para obtener un saldo positivo de la sociedad y ante el cual, lo que sí interesaba, era liberar de sus garras el preciado objeto robado.

"H ay que romantizar el mundo... - dice $\mathrm{N}$ ovalis-... Así se recupera el sentido primitivo... D ándolea lo corriente un sentido superior, a lo vulgar un aspecto misterioso, a lo conocido la dignidad de lo desconocido, así es como lo romantizo todo" (N ovalis, 1984: 112). D e esta manera D upin estaría efectuando precisamente aquello que pide $N$ ovalis: del crimen (el enigma) se dirigirá a lo 
elemental y, desde aquel lugar originario, aquel Aleph en el cual se cobija y funda la carta robada, retornará a lo misterioso del mundo portando aquellas llaves que permitirán abrir nuevamente, y cuando sea necesario, los portales de la antigua fortaleza de la edad primigenia: la poesía y la escritura.

\section{REFERENCIAS BIBLIOGRAFICAS}

Barthes, Roland. 1990. La aventura semiológica. Barcelona: Paidós.

Borges, Jorge Luis. 1979. "El cuento policial". Borges oral. Buenos Aires: Emecé. Cortázar, Julio. 1973. "Introducción a Ensayosy críticas de Edgar Allan Poe". Ensayosy críticas de Edgar Allan Poe. M adrid: Alianza.

D avidson, Javier. 1960. Poe: Estudio crítico, M éxico: Letras.

Lacan, Jacques. 1984. "El seminario de 'La carta robada". Escritos. M éxico: Siglo Veintiuno, Vol I.

Link, D aniel. 1992. El juego de los cautos. Buenos Aires: La M arca Editora.

Novalis. 1984. Escritos escogidos. M adrid: Visor.

Poe, Edgar. 1987. La carta robada. M adrid: Siruela.

- - - . 2002. La filosofía dela composición. Barcelona: Libros C. de Langre. 